\title{
USO DE OLEATO DE MONOETANOLAMINA PARA ESCLEROSE QUÍMICA EM PACIENTE COM HEMANGIOMA INTRAORAL: RELATO DE CASO
}

Elise Alves de MIRANDA, Helena Laskawski KLEMBA, Karine Fátima LYKO, José Miguel AMENÁBAR, Cassius Carvalho TORRES-PEREIRA

O hemangioma é considerado uma neoplasia vascular benigna em que a principal característica consiste na proliferação de vasos sanguíneos. Paciente de 58 anos, sexo feminino, leucoderma, encaminhada para a disciplina de Estomatologia da UFPR com queixa de "mancha no lábio inferior após mordiscamento". Durante o exame intraoral observou-se uma mácula, de coloração arroxeada, sem sintomatologia dolorosa e com limites bem definidos, medindo cerca de $5 \times 3$ milímetros. 0 exame de diascopia positivo (vitropressão) evidenciou um esmaecimento da coloração arroxeada e estabeleceu-se o diagnóstico clínico de hemangioma. A localização, tamanho e condição sistêmica da paciente determinaram a indicação e conduta terapêutica com esclerose química da lesão. $O$ tratamento consistiu na injeção de $0,05 \mathrm{~mL}$ de agente esclerosante- Ethamolin ${ }^{\circledR}$ (oleato de monoetanolamina) em 4 sessões. No decorrer das aplicações, a região tratada apresentou-se fibrosa e com coloração mais próxima àquela da mucosa normal adjacente. Na última sessão foi aplicado apenas $0,01 \mathrm{~mL}$ para conclusão do tratamento. $O$ presente relato reforça a indicação da literatura de que o tratamento esclerosante é de fácil execução, rápido e dispensa manobras invasivas. A semiotécnica de vitropressão contribui para o diagnóstico clínico e a aplicação de agente esclerosante resulta em um prognóstico favorável, com redução considerável da coloração original.

Palavras-chave: Hemangioma; Estomatologia; Escleroterapia. 